\title{
Gambaran Sikap Ibu Terhadap Perkembangan Motorik Kasar Anak Batita di Puskesmas Simpang Tiga Pekanbaru Tahun 2015
}

Attitude picture Mother Against Child Toddlers gross motor development in the health center Pekanbaru Simpang Tiga 2015

Ani Triana, Freny Chandra Leka

Program Studi DIII Kebidanan STIKes Hang Tuah Pekanbaru

\section{INTISARI}

Stimulasi adalah upaya orang tua atau keluarga untuk mengajak anak bermain dalam suasana penuh gembira dan kasih sayang. Kurangnya stimulasi dari orang tua dapat mengakibatkan keterlambatan perkembangan anak.Berdasarkan survey awal yang penelitilakukan di RumahSakitAwal Bros Periode2013 diperolehdari 70 batita mengalamigangguan tumbuh kembang terdapat 40 batita yang mengalami gangguan motorik kasar.Tujuan penelitian untuk mengetahui gambaran sikap ibu terhadap perkembangan motorik kasar pada batita di Puskesmas Simpang Tiga Pekanbaru tahun 2015

Jenis penelitian yang digunakan dalam penelitian ini adalah deskriptifkuantitatif.Populasi dalam penelitian ini yaitu seluruh ibu yang memlikibatitausia 13 tahun di PuskesmasSimpangTigapada27 Mei 2015. Dengan sampel berjumlah 40batita di PuskesmasSimpangTiga.Dengan menggunakan accidentalsampling sebagai teknik pengambilan sampeldan menggunakan analisa data univariat.

Hasil penelitian di perolehdari 40 responden yang memilikibatitamayoritas sikap positif terhadap perkembangan motorik kasarpada anak usia 1-3 tahun adalah 32 orang( $80 \%)$.

Kesimpulan penelitian ini adalah terdapat peranan yang penting dari sikap ibu dalam mempengaruhi perkembangan anak baik motorik kasar ataupun halus.Diharapkan para ibu dan orangtua mau melakukan stimulasi kepada anak demi kelancaran perkembangannya serta dapat lebih memperhatikan dan meningkatkan pemantauan terhadap tumbuh kembang anaknya.

\section{Kata Kunci : Sikap Ibu, Perkembangan motorik kasar batita, Puskesmas Simpang TigaPekanbaru}

\section{ABSTRAK}

Stimulation is the efforts of parents or relatives to invite children to play in an atmosphere of joy and affection. Lack of stimulation from parents can lead to delays in child development. Based on the initial survey researchers conducted at Hospital Awal Bros period in 2013 was obtained from 70 toddlers experiencing ganggua ntumbuh fireworks there were 40 toddlers who experience motor disturbances kasar.Tujuan research to describe the attitude of the mother towards the development of gross motor skills in toddlers year in PHC SimpangTiga Pekanbaru 2015

This type of research used in this research is quantitative descriptive. The population in this study are all mothers who possess toddlers aged 1-3 years in PHC SimpangTigapada27 May 2015. The sample was 40batita SimpangTiga health center. By using accidental sampling as sampling techniques and using univariate data analysis.

The research results perolehdari 40 respondents who memilikibatitamayoritas positive attitude towards motor development of children aged 1-3 years kasarpada is 32 people $(80 \%)$. 
The conclusion of this study is that there is an important role of the mother's attitude affects both gross motor development of children or halus.Diharapkan mothers and parents want to do the stimulation to the child for the smooth development and can pay more attention to and improve the monitoring of their children's growth.

Keywords: Attitude Mother, toddler gross motor development, PHC Pekanbaru Simpang Tiga

\section{PENDAHULUAN}

Perkembangan motorik

merupakan perkembangan

pengendalian gerakan tubuh melalui

kegiatan yang terkoordinir antara susunan

saraf, otot, otak, dan spinal cord.

Perkembangan motorik meliputi motorik

kasar dan halus. Motorik kasar adalah

gerakan tubuh yang menggunakan otot-

otot besar atau sebagian besar atau

seluruh anggota tubuh (Arfan, 2008).

Sikap seperti pandangan yang akan di berikan dalam perkembangan motorik kasar pada anak ini yaitu dengan memberikan stimulasi yaitu perkembangan memerlukan rangsangan, misalnya penyedian alat mainan, sosialisasi anak, dan mengajarkan anak sesuai dengan usianya.adapun sikap ibu yang dapat menyebabkan keterlambatan perkembangan pada anaknya yaitu dengan ibu yang kurang pengetahuan untuk menstimulus anaknya sehingga anaknya tidak dapat berkembang sesuai dengan usia nya, dibandingkan dengan sikap ibu yang memliki pengetahuan untuk perkembangan motorik kasar pada anaknya sehingga anaknya dapat melakukan apa saja yang sesuai dengan usianya (Safitri, 2012)

Orang tua memiliki peran penting dalam optimalisasi perkembangan seorang anak. Orang tua harus selalu memberikan rangsang / stimulasi kepada anak dalam semua aspek perkembangan baik motorik kasar maupun halus, bahasa dan personal sosial. Stimulasi ini harus di berikan secara rutin dan berkesinambungan dengan kasih sayang, metode bermain dan lain-lain. Sehingga perkembangan anak akan berjalan optimal. Kurangnya stimulasi dari orang tua dapat mengakibatkan keterlambatan perkembangan anak, karena 
itu para orang tua atau pengasuh harus

diberi penjelasan cara-cara melakukan

stimulasi kepada anak-anak (Dinkes, 2009).

Berdasarkan survey awal yang peneliti lakukan di Rumah Sakit Awal Bros Periode 2013 terdapat kasus gangguan tumbuh kembang pada batita sebanyak 70 batita, dari 70 batita yang mengalami tumbuh kembang terdapat 40 batita yang mengalami gangguan motorik kasar dan 30 batita mengalami tumbuh kembang motorik halus, karena Rumah Sakit Awal Bros tidak bisa di lakukan penelitian dan membutuhkan waktu yang lama, maka peneliti mengambil tempat sejalan,dan brada dalam satu wilayah di Pekanbaru dengan Rumah sakit tersebut ke Puskesmas Simpang Tiga Pekanbaru, Jadi Peneliti mengambil temepat penelitian di Puskesmas Simpang Tiga Pekanbaru Tahun 2015

Berdasarkan masalah tersebut maka peneliti merasa tertarik untuk meneliti tentang "Gambaran sikap ibu terhadap motorik kasar pada anak batita di Puskesmas simpang Tiga Pekanbaru Tahun 2015",

Penelitian ini dilakukan untuk mengetahui gambaran sikap ibu terhadap perkembangan motorik kasar pada batita di Puskesmas Simpang Tiga Pekanbaru 2015 METODE

Jenis penelitian yang digunakan adalah penelitian deskriptif kuantitatif yaitu penelitian yang menggambarkan atau mendeskripsikan gambaran sikap ibu terhadap perkembangan motorik kasar batita usia 1-3 tahun Di Puskesmas Simpang Tiga Tahun 2015.

Sampel dalam penelitian ini adalah seluruh ibu yang memiliki anak usia 1-3 tahun pada bulan Mei berjumlah 40 batita di Puskesmas Simpang Tiga

Setelah data diolah, maka peneliti melakukan analisa data univariat yang digunakakn untuk mendapatkan distribusi gambaran pengetahuan. 
HASIL

1. Karakteristik Responden

Tabel 1

Karakteristik Responden Berdasarkan

Umur

\begin{tabular}{cccc}
\hline $\begin{array}{c}\text { No } \\
\text {. }\end{array}$ & Umur & $\begin{array}{c}\text { Frekuen } \\
\text { si }\end{array}$ & $\begin{array}{c}\text { Persenta } \\
\text { si }\end{array}$ \\
\hline 1. & $\begin{array}{c}20-25 \\
\text { tahun }\end{array}$ & 7 orang & $17,5 \%$ \\
2. & $\begin{array}{c}26-30 \\
\text { tahun } \\
\text { 3a }\end{array}$ & 24 orang & $60,0 \%$ \\
3. & $\begin{array}{c}> \\
\text { tahun }\end{array}$ & 9 orang & $22,5 \%$ \\
\hline & $\begin{array}{c}\text { Jumla } \\
\text { h }\end{array}$ & 40 orang & $100 \%$ \\
\hline
\end{tabular}

dari hasil penelitian dapat di lihat
Puskesmas Simpang Tiga mayoritas berumur 26-30 sebanyak 24 orang $(60,0 \%)$

a. Karakteristik berdasarkan pendidikan

Tabel 2

Karakteristik Responden

Berdasarkan Pendidikan

\begin{tabular}{cccc}
\hline No & $\begin{array}{c}\text { Pendidika } \\
\text { n }\end{array}$ & $\begin{array}{c}\text { Frekuens } \\
\text { i }\end{array}$ & $\begin{array}{c}\text { Persentas } \\
\text { i }\end{array}$ \\
\hline 1. & Rendah & 14 orang & $35,0 \%$ \\
2. & Tinggi & 26 orang & $65,6 \%$ \\
\hline & Jumlah & 40 orang & $100 \%$ \\
\hline
\end{tabular}

dari hasil penelitian dapat di lihat bahwa sebagian besar responden di Puskesmas Simpang Tiga mayoritas berpendidikan tinggi 26 orang $(65,6 \%)$

bahwa sebagian besar responden di

\section{Analisa Univariat}

Tabel 4

Distribusi Frekuensi Pendidikan dengan Sikap Ibu di Puskesmas Simpang Tiga Kota Pekanbaru

\begin{tabular}{|c|c|c|c|c|c|c|c|}
\hline \multirow{3}{*}{ Pendidikan } & \multicolumn{4}{|c|}{ Sikap ibu } & & & \multirow{3}{*}{$\begin{array}{c}P \\
\text { Value }\end{array}$} \\
\hline & \multicolumn{2}{|c|}{ Negatif } & \multicolumn{2}{|c|}{ positif } & \multicolumn{2}{|c|}{ Total } & \\
\hline & F & $\%$ & $\mathrm{~F}$ & $\%$ & $\mathrm{~F}$ & $\%$ & \\
\hline Rendah & 13 & 64,1 & 2 & 35,9 & 15 & 100 & \\
\hline Tinggi & 3 & 30,6 & 22 & 69,4 & 25 & 100 & 0.004 \\
\hline Total & 16 & 45,5 & 24 & 54,5 & 40 & 100 & \\
\hline
\end{tabular}

Berdasarkan tabel 4 diketahui bahwa dari

40 responden mayoritas memiliki sikap positif terhadap perkembangan motorik kasar pada batita sebanyak 24 orang ( 54,5

$\%$ ) dan yang memiliki sikap negatif sebesar 16 orang (45,5\% ) 
Tabel 5

Distribusi Frekuensi umur dengan Sikap Ibu di Puskesmas Simpang Tiga Kota Pekanbaru

\begin{tabular}{|c|c|c|c|c|c|c|c|}
\hline \multirow{3}{*}{ Umur } & \multicolumn{4}{|c|}{ Sikap ibu } & & & \multirow{3}{*}{$\begin{array}{c}P \\
\text { Value }\end{array}$} \\
\hline & \multicolumn{2}{|c|}{ Negatif } & \multicolumn{2}{|c|}{ positif } & \multicolumn{2}{|c|}{ Total } & \\
\hline & F & $\%$ & F & $\%$ & $\mathrm{~F}$ & $\%$ & \\
\hline $20-25$ & 10 & 25,1 & 2 & 9,1 & 12 & 100 & \\
\hline $26-30$ & 3 & 10,2 & 20 & 36,3 & 23 & 100 & \\
\hline$>30$ & 3 & 10,2 & 2 & 9,1 & 5 & 100 & \\
\hline Total & 16 & 45,5 & 24 & 54,5 & 40 & 100 & \\
\hline
\end{tabular}

Berdasarkan tabel 5 diketahui bahwa dari 40 responden mayoritas memiliki sikap positif terhadap perkembangan motorik kasar pada batita dengan umur 2630 sebanyak 20 orang ( $36,3 \%$ ).

\section{PEMBAHASAN}

Berdasarkan hasil penelitian dapat diketahui bahwa dari 40 responden yang memiliki sikap positif terhadap perkembangan motorik kasar anak batita adalah 32 orang ( $80 \%$ ) dan yang memiliki sikap negatif sebesar 8 orang ( 20 $\%)$.

Sikap merupakan reaksi atau respons seseorang masih tertutup terhadap suatu stimulus atau objek. Menurut Newcomb, sikap merupakan kesiapan atau kesediaan untuk bertindak dan bukan merupakan pelaksana motif tertentu. Sikap belum merupakan suatu tindakan atau aktifitas akan tetapi predisposisi tindakan atau perilaku. Sikap masih merupakan reaksi tertutup, bukan merupakan reaksi terbuka tingkah laku yang terbuka (Notoadmodjo, 2007).

Peran aktif orang tua terhadap perkembangan anak-anaknya sangat diperlukan terutama pada sat mereka masih dibawah usia 3tahun (Batita). Seorang anak yang baru lahir secara mutlak bergantung pada lingkungannya, supaya ia dapat melangsungkan kehidupan dan mengembangkan kemampuan dasar yang dimilikinya (Suherman, 2000). 
Peran yang dimaksud adalah usaha langsung terhadap anak, dan peran lain yang penting adalah dalam menciptakan lingkungan rumah sebagai lingkungan sosial yang pertama dialami anak. Dari ucapan dan tingkah laku orang tua yang konsisten,anak memperoleh perasaan aman,mengetahui apa yang diharapkan dari hubungan antar-manusia,serta membangun pengertian yang jelas tentang apa yang benar dan apa yang salah. Sejak lahir anak sudah membutuhkan kasih sayang, rasa aman dalam suasana hubungan dengan orang lain yang stabil dan menyenangkan, penghargaan dan pujian apa bila anak melakukan hal-hal yang baik dan benar serta belajar bertanggung jawab agar anak lebih mandiri.Setelah mengetahui peran aktif orangtua terhadap perkembangan anak, maka alangkah baiknya bila kita mengetahui bagaimana sikap orang tua dalam keluarga dan kemungkinannya akibatnya yang akan timbul bagi perkembangan anak. Ada tiga jenis sikap orangtua dalam keluarga yang berpengaruh terhadap tumbuh kembang anak,yaitu sikap otoriter,liberal dan demokrasi (Suherman, 2000).

Hal ini sesuai dengan penelitian dengan penelitian Sari, dkk (2012) tentang Hubungan Pengetahuan dan Sikap Ibu dengan Perkembangan Motorik Kasar Anak Batita di Paud Ngudi Rahayu Larep Kecamatan Ungaran Barat Kabupaten Semarang diketahui bahwa dari 30 responden mayoritas ibu yang memiliki sikap baik terhadap perkembangan anak sesuai tahap perkembangannya sebanyak 21 responden $(70 \%)$.

Peneliti berasumsi bahwa sikap dan peran orangtua terutama ibu sangat diperlukan dalam tahapan perkembangan motorik kasar anak terutama diusia batita, karena dengan adanya dukungan dari ibu maka si anak akan lebih percaya diri dalam mengembangkan keaktifannya serta lebih terjaga apa yang dilakukannya sehingga keamanan si anak tetap terjaga. 
Orangtua juga dapat memberikan stimulasi yang dibutuhkan sesuai umur anak untuk membantu merangsang anak dalam mengembangkan kemampuannya melakukan hal-hal yang merupakan motorik kasar ataupun motorik halus.

\section{KESIMPULAN}

Berdasarkan penelitian yang telah dilakukan di Puskesmas Simpang Tiga Kota Pekanbaru tentang gambaran sikap ibu terhadap perkembangan motorik kasar pada batita didapatkan hasil dari 40 responden yang memiliki sikap positif terhadap perkembangan motorik kasar pada batita adalah 32 orang ( $80 \%$ ) dan yang memiliki sikap negatif sebesar 8 orang ( $20 \%$ ).

\section{SARAN}

Diharapkan hasil penelitian ini dapat menjadi tolak ukur serta motivasi untuk meningkatkan penyuluhan atau memberikan contoh kepada ibu-ibu yang memiliki batita agar dapat meningkatkan peran aktifnya terhadap perkembangan dan pertumbuhan anaknya serta dapat memberikan contoh stimulasi yang dapat diberikan orangtua pada anaknya terutama pada perkembangan motorik kasar anak sehingga tidak ada lagi ibu yang mempunyai sikap negatif terhadap perkembangan motorik kasar pada batita.

\section{DAFTAR PUSTAKA}

Androskripsi. (2012).Gambaran pengetah uan dan sikap ibu. http://androskripsi.com.diakses.Diak sestanggal 20 februari 2013

Angela. (2013).50-persen-balita-indonesiamengalami-gangguanpertumbuhan. Htmhttp://www.jogjav.tv.

Diaksestanggal 20 februari 2013

Arif.(2011).mengenal, danmengobatigangguankesehatanpa dabalita. Yogyakarta: titano

Arikunto.(2006).prosedurpenelitiansuatup endekatanpraktik. Jakarta: rinekacipta

Aziz.(2009).

Pengantarilmukeperawatananak.Jak arta: salembamedika

Susanto. (2011). Perkembangan anak usia dini. Jakarta : Kencana Predana

Dian.(2009).

Tumbuhkembangdanterapibermainp adaanak. Jakarta: Salembamedika

Notoadmojo.(2007).

Promosikesehatan\&ilmuperilaku. Jakarta: rinekacipta 
Vivian.(2010).

Asuhanneonatusbayidananakbalita.J akarta: salembamedika
Yunita.(2010).

Gambaranpengetahuandansikapibu.

Diaksestanggal 2011

Widyastuti.(2001).

Panduanperkembangananak 0 -

1.Jakarta: puspaswara 